\title{
COMMON PROBLEMS OF TEACHING RUSSIAN VERBS TO PERSIAN LANGUAGE STUDENTS USING RUSSIAN-PERSIAN BILINGUAL DICTIONARIES AS A TEACHING TOOL
}

Mohammadi Mohammad Reza, Ahmadi Mireyla, Baharloo Hadi, Ghalebandi Seyedeh Safoora

Tarbiat Modares University,

address: Iran, Tehran, Jalal AleAhmad, Nasr, P.O.Box: 14115-111

\begin{abstract}
This article studies the Russian verb and its grammatical and semantic information in three dictionaries by Klevtsova S. D., Voskanyan G.A., Ovchinnikova I.K., which are the most relevant dictionaries at present and most often used while learning the Russian language in Iranian universities. In this work the problems with which Iranian students are faced while searching verb forms in these dictionaries are considered. By comparing these dictionaries in terms of the content and information contained in each entry, the author lists the differences between these dictionaries and points out the lack of some information necessary for Iranian students to learn. It seems that updating the content of the mentioned dictionaries will not only help to optimize the Russian language learning process by Iranian students at different educational levels, but also to solve translation problems.
\end{abstract}

Key Words: verb, teaching, Persian language student, bilingual dictionary, Russian-Persian dictionary

For citation: Mohammadi Mohammad Reza, Ahmadi Mireyla, Baharloo Hadi, Ghalebandi Seyedeh Safoora 2020. Common Problems of Teaching Russian Verbs to Persian Language Students Using Russian-Persian Bilingual Dictionaries as a Teaching Tool. Philological Sciences at MGIMO. Vol. 6. No 4(24). P. 103-111. https://doi.org/10.24833/2410-2423-2020-4-24-103-111

\section{ТИПИЧНЫЕ ПРОБЛЕМЫ ОБУЧЕНИЯ РУССКОМУ ГЛАГОЛУ ИРАНСКИХ СТУДЕНТОВ ПРИ УПОТРЕБЛЕНИИ ДВУЯЗЫЧНЫХ РУССКО-ПЕРСИДСКИХ СЛОВАРЕЙ КАК СРЕДСТВ ОБУЧЕНИЯ}

Мохаммади Мохаммад Реза, Ахмади Мирейла, Бахарлу Хади, Галебанди Сейеде Сафура

Государственный университет Тарбиат Модарес.

Иран, Тегеран, проспект Джалал Але Ахмад, университет Тарбиат Модарес, 14115-111. 


\begin{abstract}
Аннотация. Данная статья посвящена русскому глаголу и его грамматическим и тексическим характеристикам в трёх русско-персидских словарях: С.Д. Клевиовой., Г.А. Восканяна, а также И.К. Овчинниковой, являющихся на сегодняшний день наиболее авторитетными словарями при изучении русского языка в иранских вузах. В работе анализируются трудности, возникающие у иранских студентов при поиске глагольных форм в указанных стоварях. Сравнивая вышеназванные словари по содержанию информации, включённой в каждое гнездо заголовочного слова, авторы анализируют трудности, с которыми сталкиваются иранские студенты при изучении представленного в них лексического и грамматического материала. Рассматривая данные словари в качестве средств обучения, авторы предприняли попытку показать необходимость обновления не только содержащихся в них грамматических сведений о русских глаголах, но и их значений. Представляется, что обновление вышеупомянутых русско-персидских словарей не только поможет оптимизации процесса изучения русского языка иранскими студентами на разных уровнях обучения, но и устранит проблемы, возникающие в процессе перевода с русского на персидский язык.
\end{abstract}

Ключевые слова: глагол, обучение, иранский студент, двуязыцный словарь, русско-персидский словарь

Для цитирования: Мохаммади Мохаммад Реза, Ахмади Мирейла, Бахарлу Хади, Галебанди Сейеде Сафура 2020. Типичные проблемы обучения русскому глаголу иранских студентов при употреблении двуязычных русско-персидских словарей как средств обучения. Филологические науки в МГИМО. Том 6. № 4(24). С. 103-111. https://doi.org/10.24833/2410-2423-2020-4-24-103-111

Д

ля обучения ИЯ ${ }^{1}$ используются различные средства, обусловливающие эффективность учебного процесса. Разнообразные средства обучения призваны оказывать помощь обучающимся при восприятии и запоминании нового материала, а также в ходе отработки практических навыков.

По словам А.Н. Щукина, в структурном отношении в системе обучения ИЯ принято выделять средства обучения для преподавателя, для учащихся, $\mathrm{ABCO}^{2}$, а также $\mathrm{TCO}^{3}$. Последняя разновидность средств адресуется как преподавателю, так и обучающимся [5, с. 213].

Одним из важнейших средств обучения, предназначенных для иностранных учащихся, можно считать словарь. Словарь в качестве необходимого каждому обучающемуся источника не только является помощником в процессе изучения ИЯ в различных коммуникативных, профессиональных и переводческих деятельностях, но и способствует развитию разных видов речевой деятельности как на иностранном, так и на родном языке [3, с. 81].

В настоящее время в мире существуют разнообразные энциклопедические и языковые (лингвистические) словари, которые по-разному оказывают помощь своим пользователям при устранении различных языковых проблем. При рассмотрении средств обучения ИЯ можно особо отметить двуязычные словари.

Задачи, решаемые двуязычными словарями, охватывают самые разные области науки и практики, например, обучение иностранному языку и переводу при компетентностном подходе в условиях непрерывного образования, теории массовой коммуникации, теорию и практику научно-технической информации, переводоведение и многие другие [2, с. 84].

Когда речь идёт о словарях, особенно двуязычных, мы замечаем, что большинство иностранных студентов не умеет работать с таким словарем. Зачастую студенты вообще не считают, что данный источник может выступать в качестве эффективного средства обучения. Большое количество студентов воспринимает любой словарь как архив значений слов, а если это двуязычный словарь, - то как хранилище существующих значений иностранного языка. В настоящее время

\footnotetext{
Иностранный язык

Аудиовизуальные средства обучения

Технические средства обучения
} 
существенные трудности заключаются в неумении обучающихся правильно использовать двуязычные словари. Такая проблема затрудняет весь процесс обучения [7, с. 166]. Опыт преподавания в иранских вузах свидетельствует о существовании данной проблемы в группах, где иранские студенты занимаются изучением русского языка.

Объектом исследования данной статьи является русский глагол, способы его употребления, а также его грамматические и лексические характеристики в исследуемых двуязычных словарях. Также анализируются трудности, возникающие у иранских студентов в ходе поиска глагольных форм в русско-персидских словарях. Авторы также проводят анализ эквивалентов некоторых частотных русских глаголов на персидском языке в двуязычных словарях. Предполагается, что рассмотрение этих проблем поможет устранить трудности, возникающие при изучении русского глагола студентами иранской аудитории.

Необходимо отметить, что предметом исследования стали глаголы, представляющиеся нам наиболее употребительными. Они были отобраны из «Частотного словаря русского языка» под ред. Л.Н. Засориной [9]. Кроме того, большая часть данной работы посвящена рассмотрению производных глаголов русского языка. Причина данного выбора состоит в том, что трудности, испытываемые иранскими студентами при работе с указанными словарями, в наибольшей степени связаны с производными глаголами.

В настоящее время в Иране существуют различные русско-персидские словари, среди которых наиболее авторитетными являются «Русско-персидский словарь» С.Д. Клевцовой (под редакцией Г.А. Восканяна) [4], «Русско-персидский словарь» Г.А. Восканяна [1], а также «Русско-персидский словарь» И.К. Овчинниковой [6]. Поскольку основным предметом данной исследовательской работы является изучение глагола, в работе предпринята попытка представить необходимую информацию об оформлении глаголов в упомянутых словарях.

Ниже мы приводим общие сведения об этих словарях, демонстрирующие существенные различия между ними.

1. Русско-персидский словарь С.Д. [4] - двуязычный переводной и учебный словарь, содержащий около 11000 слов, предназначенный в частности для иранских студентов, изучающих русский язык с преподавателем или самостоятельно. Ниже перечисляются некоторые особенности подачи глаголов в данном словаре:

1.1. В данном словаре даются переводы при глаголах $\mathrm{HCB}^{4}$, a $\mathrm{CB}^{5}$ приводятся в словарном порядке по алфавиту со ссылкой на глагол НСВ. Например:

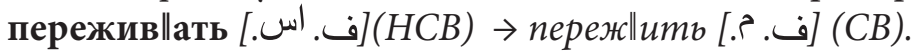

Наблюдается и исключение: если глагол СВ считается более частотным, тогда переводы даются при глаголах СВ: взглян $\|$ yть.

1.2. Если одно из значений глагола используется только в одном виде, тогда к нему даётся по-

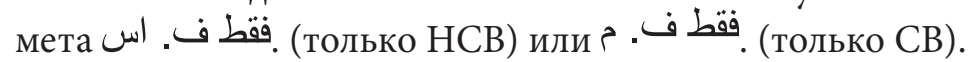

1.3. Грамматические формы НСВ и СВ приводятся, как правило, в статье НСВ глагола. После перечислении грамматических форм НСВ в той же статье разрядкой даётся глагол СВ, а также его транскрипция и грамматические формы. Причём при глаголах НСВ даются формы первого и второго лица единственного числа настоящего времени.

1.4. Для глаголов неправильного образования, возвратных глаголов и глаголов второго спряжения даются также формы прошедшего времени (все роды, а также множественное число), форма повелительного наклонения после пометы 1 (повелительное наклонение). В глаголах СВ даются формы первого и второго лица единственного числа.

1.5. Глаголы СВ, образованные от глаголов НСВ путём присоединения префикса к глаголу, часто имеют те же окончания, что и НСВ в настоящем времени. Таким образом, формы глагола СВ отдельно не приводятся, если ударение у них одно и то же. Например: гуля\|mь - по|гулять.

\footnotetext{
4 Несовершенный вид

Совершенный вид
} 
1.6. При глаголах и их значениях, которые обязательно требуют дополнения, указываются падежные вопросы: кого-чего (род. падеж) и т.д. [там же, с.3-7, 10-12].

2. Русско-персидский словарь Г.А. Восканяна [1] - прежде всего словарь, предназначенный для русскоговорящих студентов, преподавателей, переводчиков, научных и практических работников. Кроме того, словарь может быть использован при чтении художественной и политической литературы на русском языке пользователями, для которых персидский язык является родным языком. Объём данного гнездового словаря - около 30000 слов современного русского литературного языка. Характерная особенность данного словаря состоит в том, что он включает общественно-политическую лексику, а также научно-технические и специальные термины. Надо отметить, что словарь снабжён приложениями следующего содержания: список широкоупотребляемых буквенных сокращений, список неправильных глаголов, а также основные правила практической транскрипции в латинской графике. Ниже приводятся основные сведения о словаре:

2.1. Данный русско-персидский словарь - это алфавитно-гнездовой словарь, в котором заглавные слова располагаются в алфавитном порядке, а однокоренные с ними слова объединяются в одну статью-гнездо. При этом неизменяемая заглавная часть отделяется в заглавном слове при помощи параллельки $(\|)$, а остальные слова, объединённые в одно гнездо, заменяются тильдой $(\sim)$.

2.2. В словарной статье слова располагаются в алфавитном порядке, за исключением случаев, когда в алфавитном соседстве представляются видовые пары основных глаголов и их возвратные формы. Чтобы избежать повторения, перед заглавным словом данной статьи-гнезда ставят звездочку $\left.{ }^{*}\right)$. Пары-омонимы приводятся самостоятельно. Например:

*закрепllить сов., закреплять несов. ...| иться сов., ляться несов.

2.3. В тех случаях, когда обычный порядок видовых пар (СВ после НСВ) меняется, тогда видовые формы даются с пометами вида. Например: задержать сов., задерживать несов. ...

2.4. В тех случаях, когда значения глагола НСВ имеют разные видовые пары, тогда последние приводятся к соответствующим значениям данного глагола. Например:

валять, вывалять, свалять 1. сов. вывалять 2. сов. свалять

Если же одно или несколько значений глагола употребляются только в НСВ, к этим значениям даётся соответствующая помета. Например:

выходить, выйти 1 ...2 тк. несов. (быть обращённым в какую-л. сторону).

2.5. При однокоренных глаголах перевод приводится только в том случае, если он отражает конкретное значение глагола, а в остальных случаях даётся ссылка к НСВ с пометой СВ однокоренного глагола:

махнуть сов. 1. однокр. см. махать 2....

2.6. Часто происходит так, что страдательный залог глагола при переводе персидскими грамматическими формами не включается. Включаются только те формы глагола, которые передаются лексически на персидский язык (с пометой страд. и переводами):

Выполняться несов. страд. انجام يافتن، اجر ا شُن

2.7. Глагольное русское управление вообще не указывается [там же, с. 9-10]

3. Русско-персидский словарь И.К. Овчинниковой [6]:

Данный словарь предназначен для русскоязычных преподавателей, переводчиков и студентов. Данный словарь включает 36000 слов и в сравнении с двумя рассмотренными выше словарями является более объёмным. В нём каждое заглавное слово со всеми относящимися к нему словами даётся в одной статье. Перед каждым заглавным словом приводятся все необходимые грамматические, стилистические и специальные пометы, а также перевод этого слова на персидский язык с транскрипцией.

Если рассматривать характеристики русских глаголов, представленные в данном словаре, можно указать на следующие особенности:

3.1. Если значение глагола НСВ шире, чем глагола СВ, после отсылки к СВ приводятся эквиваленты на персидском языке, присущие только НСВ: 
Досматривать несов. 1. см. досмотреть; 2. (производить досмотр) بازرسى كазрӓси к,

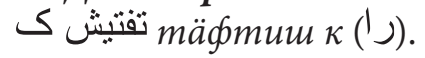

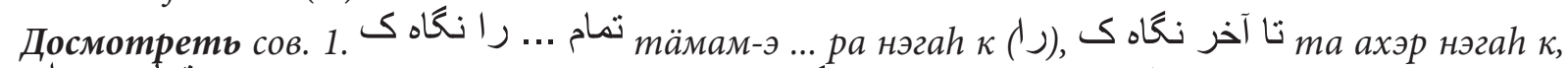

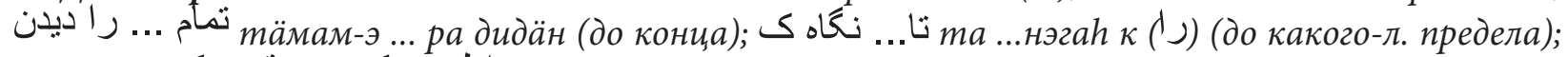
2.: не مواظبت نكردن، دقت نكردن

3.2. В тех случаях, когда глагол СВ и НСВ переводятся по-разному, значения даются отдельно:

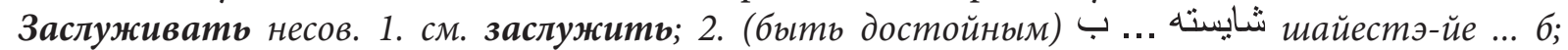

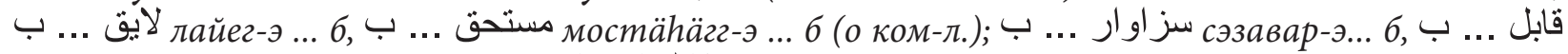
габэл-е... б (о чём-л.); доверия

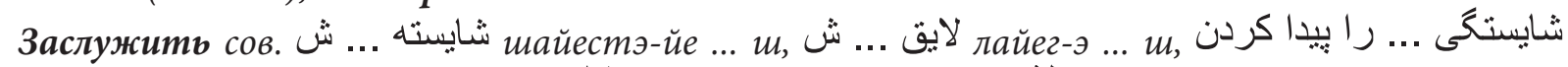

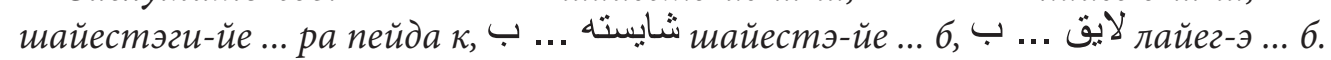

3.3. Наиболее частотные вспомогательные глаголы в составе персидских сложных глаголов даются сокращённо, указывается лишь их первая буква, как в графике, так и в транскрипции:

آ آ آ - آد

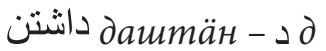

3.4. После перевода глагола на персидский язык в скобках приводятся все возможные варианты глагольных управлений. Например:

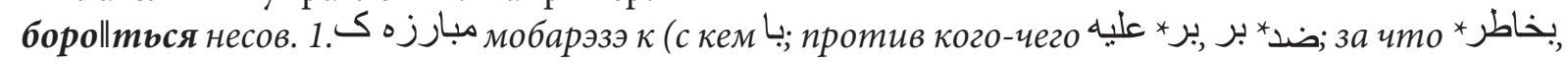

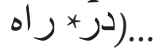

3.5. Как подчёркивает автор в предисловии, в словарь не включены стандартные формы глаголов. В тех случаях, когда глагол НСВ помимо страдательного обладает и средним значением, тогда среднее значение даётся с переводом или отсылкой к соответствующему глаголу СВ, а страдательное значение - с указанием на исходную форму действительного залога НСВ с отсылкой к глаголу СВ, снабжённому переводом:

Сжиматься несов. 1. см. сжаться; 2. страд. к жимать (см. сжать I)

[там же, с. 14-17].

Исходя из анализа глагольных форм русского языка, содержащихся в трёх рассмотренных нами словарях, можно отметить следующие проблемы, затрудняющие работу с данными словарями для иранских студентов.

1. Прежде всего, рассмотрим русско-персидский словарь С.Д. Клевцовой [4].

1.1. Одна из важнейших проблем относится к содержанию словаря С.Д. Клевцовой. В предисловии к данному словарю автор подчёркивает, что при его составлении были использованы учебные словари на других языках: например, Русско-английский учебный словарь Б.А. Лапидуса и С.В. Шевцовой (1962), а также Частотный словарь современного русского литературного языка Э.А. Штейнфельдта (1963) [там же, с. 1].

В данном словаре можно заметить отсутствие некоторых частотных производных глаголов современного русского языка, в особенности приставочных глаголов, которые можно встретить в русских учебниках, предназначенных для иностранных студентов: «проживать-прожить», «передаваться - передаться», «задаваться - задаться».

1.2. В предисловии к словарю С.Д. Клевцовой отмечено, что для поиска глагола СВ необходимо обращаться к его видовой паре НСВ. Например: оказаться оказываться هі; nepenymamb nерепутывать نи и.д.

Существуют глаголы СB, которые не выделяются в корпусе словаря отдельно, а только помещаются в ту статью, где дана их видовая пара НСВ. Например, частотный приставочный глагол «заработать», который не приводится на своём алфавитном месте со ссылкой на глагол НСВ, но его можно найти в словарной статье его видовой пары «зарабатыьвать». Таким образом, в случае незнания видовой пары данных приставочных глаголов иранские студенты не смогут их найти.

1.3. Выше было отмечено, что в словаре С.Д. Клевцовой при глаголах и их значениях, которые обязательно требуют дополнения, указываются падежные вопросы. Здесь обучающиеся также сталкиваются с рядом проблем, связанных с глагольным управлением. Перечислим некоторые 
из них: 1) глаголы «прибывать-nрибыть», требующие глагольного управления «куда?», которого нет в словаре. Сюда эта пара включена без управления. 2) глагол «поговорить», единственное управление, указанное в словаре, - творительный падеж (с кем?), в то время как в толковых словарях русского языка для данного глагола приводится управление также в предложном падеже - «с кем - о чем?». 3) для пары «задавать - задать» в толковых словарях русского языка приводится управление «что - кому?», в данном словаре управление «кому?» отсутствует.

2. Второй анализируемый нами словарь - Русско-персидский словарь Г.А. Восканяна [1].

Рассматривая приставочные глаголы, включённые в гнездо соответствующего заголовочного слова, сталкиваемся с приставочными глаголами, для которых не отведена отдельная статья. Чтобы их найти, необходимо зайти в ту статью-гнездо, в которую включено однокоренное с ними слово. В качестве примера приводим две частотные приставочные пары:

2.1. Паре «подписывать - подписать» не посвящена отдельная статья, она включена в гнездо заголовочной статьи «подписка». Вопрос, на который необходимо обратить внимание, - наличие в словаре других однокоренных этой паре слов (подписание, подписанный, подпись). Иранским студентам младших курсов часто трудно найти необходимую им видовую пару. Причина этой трудности состоит в том, что студенты на начальных этапах обучения, встречая однокоренные слова в алфавитном порядке (подписание, подписанный, подпись и подписка), считают, что нужной им глагольной пары нет в словаре.

2.2. Другим примером можно считать частотный глагол «написать» - видо-временная форма частотного глагола НСВ «nисать». Несомненно, идя по алфавитному порядку, студенты сталкиваются с первым заглавным словом «написание», где отмечено, что для обнаружения глагола «написать» необходимо обращаться к глаголу «писать», в то время как этот глагол включён в статью-гнездо однокоренного с ним слова «писатель».

Таким образом, указанные проблемы затрудняют работу с данными словарями (особенно студентам младшего курса). Причины можно перечислить в нескольких пунктах:

1) Ознакомление с основными грамматическими характеристиками русского глагола считается важным для тех, кто начинает изучать этот предмет. Поскольку этот словарь рассчитан на русскоязычную аудиторию, в нём, в отличие от учебного словаря С.Д. Клевцовой, не приводятся формы спряжения глаголов, а также управление глагола (падежных форм управления не существует в персидском языке). Считаем необходимым включение глагольного управления в русско-персидские словари, чтобы иранские студенты при переводе могли их найти.

2) Основные и возвратные глаголы не смешиваются в отдельной статье-гнезде. Поскольку иранские студенты младшего курса часто не имеют никакого представления о частице -ся в сочетании с глаголами, им трудно найти нужные возвратные глаголы. Представляется, что ознакомление со словообразованием русских слов, в том числе глаголов, является важнейшим фактором, помогающим эффективно использовать данный словарь.

3. Далее рассмотрим «Русско-персидский словарь» И.К. Овчинниковой [6].

3.1. Способ оформления слов, в частности глаголов, в данном словаре несколько отличается от других словарей. Например, в отличие от двух предыдущих словарей, для того чтобы найти значения глаголов, нужно обращаться к той статье, куда включен глагол СВ. Кроме того, при оформлении глагольной статьи автор предусматривает некоторые правила, ознакомление с которыми необходимо для всех, кто использует данный словарь.

Как уже выше было отмечено, в словарь не вошли стандартные формы глаголов. В связи с этим, перед тем как использовать данный словарь (как любой словарь) в иранской аудитории, считается необходимым познакомить иранских студентов с правилами использования данного словаря.

3.2. В предисловии к данному словарю было отмечено, что после перевода глагола на персидский язык в скобках даются все возможные варианты глагольного управления. Однако этот принцип не соблюдается при подаче некоторых глаголов, рассмотренных нами. Например, при приставочных глаголах «переживать - пережить», «издавать - издать», «задавать - задать», «придавать - придать» и т.д. Как было подчёркнуто выше, в персидском языке падежного 
управления не существует. Таким образом, студенты младшего курса при использовании данного словаря часто сталкиваются с проблемами.

Кроме вышеперечисленных проблем, касающихся использования данных словарей в отдельности, необходимо обратить внимание на общие трудности, с которыми сталкиваются иранские студенты при обращении к ним в процессе изучения русского языка:

Один из важнейших вопросов при изучении русских приставочных глаголов - употребление приставочных глаголов в сочетании с разными предлогами. Например: «вчитываться - вчитаться» + «во что», «дочитьвать - дочитать» + «до чего» и т.д.

Хотя словарь С.Д. Клевцовой считается учебным словарем, в нём этот важный вопрос не освещается вообще, а в остальных словарях редко обращается внимание на данную проблему. Например: отсутствие управления приставочного глагола «договариваться», употребляемого с предлогом «до»+ P.n. ${ }^{6}$ существительного; приставочного глагола «выписывать» + предлог «из» + P.n. Опыт преподавания в иранской аудитории показал: вопреки тому, что понимание и употребление данных глагольных форм, по-видимому, считается несложным для иранских студентов старших курсов, студентам младших курсов зачастую трудно понимать и использовать их в своей письменной и устной речи. Причина данной проблемы состоит в том, что студенты не знакомы со способами русского глагольного словообразования, которые не присущи персидскому глаголу. Представляется важным объяснение этих вопросов преподавателями русского языка в иранской аудитории, чтобы устранить возникновение трудностей при использовании толковых русских словарей иранскими студентами.

Обобщая все упомянутые проблемы, касающиеся рассмотренных словарей, укажем и на проблемы, требующие обновления содержания словарей. Например, отсутствие множества частотных глаголов, и в особенности их управления, а также отсутствие некоторых лексических значений при глаголах. В приведённой ниже таблице предлагаем некоторые значения русских глаголов, которые можно добавить. Чтобы продемонстрировать отсутствие некоторых значений в русско-персидских словарях, рассматривалось основное значение глаголов в «Толковом словаре современного русского языка Д.Н. Ушакова» [8].

\begin{tabular}{|c|c|c|c|}
\hline № & Русский глагол & $\begin{array}{l}\text { Основное значение в Толковом словаре } \\
\text { современного русского языка Д.Н. Ушакова }\end{array}$ & $\begin{array}{c}\text { Предлагаемое значение на персидском языке, которое } \\
\text { можно добавить в русско-персидские словари }\end{array}$ \\
\hline 1. & nобыть & Остаться, пробыть недолгое время. & 'كمى ماندن 'немного остаться' \\
\hline 2. & оговориться & $\begin{array}{l}\text { 2. Ошибиться в речи, употребив другое, не } \\
\text { то, которое нужно, слово; случайно или } \\
\text { бессознательно сказать не то, что нужно. }\end{array}$ & 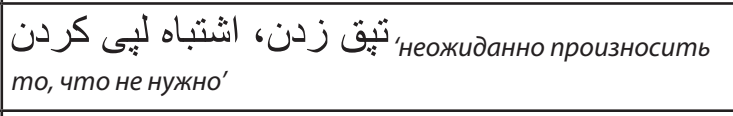 \\
\hline 3. & neредать & 1. кого-что. Вручить, отдать кому-н. & بدست كسى رساندن 'nередать кому-нибудь' \\
\hline 4. & поговорить & 1. Провести время в разговоре. & ' 'провести некоторое время в разговоре' \\
\hline
\end{tabular}

Следующая проблема, с которой часто сталкиваются иранские студенты младших курсов, относится к непониманию принципов построения русско-персидских словарей. Например: Кому адресуется данный словарь? Как включены в него разные части речи? Что обозначают аббревиатуры? и т.д. В процессе изучения русских глаголов студенты на начальных этапах учёбы зачастую не знают, как найти нужную им информацию. Это приводит к возникновению больших сложностей для студентов, пользующихся двуязычными словарями. Рекомендуется тем, кто занимается преподаванием русского языка (особенно на начальных этапах обучения), составить такой учебный план, при котором было бы возможно познакомить студентов с основными характеристиками данных словарей и научить их правильному использованию каждого из них. Иными словами, следует знакомить студентов со словарем как с одним из важнейших учебных средств, помогающих лучше и проще изучать русский язык.

\footnotetext{
6 Родительный падеж
} 
Словарь (в том числе двуязычный словарь) является хранилищем слов, а также важнейшим и достоверным источником, отражающим различные сведения о словах на разных языках мира. Таким образом, считается необходимым обновление и всестороннее рассмотрение двуязычных русско-персидских словарей и в Иране, и в России. Также придерживаемся мнения, что иранские преподаватели на занятиях по русскому языку должны уделять больше внимания изучаемым глаголам и знакомить студентов с вопросами, отсутствующими в словарях или в учебниках.

В качестве рекомендации можно предложить идею о составлении учебного русско-персидского словаря наиболее частотных глаголов, так как основная проблема заключается в передаче семантики разными языковыми средствами (в русском языке - средства аффиксации (переводить, доводить и т.д.), в персидском - разные лексические единицы (انتقال كردن، ترجمه كردن؛ رساندن) хотя средства аффиксации тоже присутствуют, в частности префиксальные глаголы (برداشتنт.д.

В качестве отдельного приложения предлагаем включать нужные сведения о грамматических категориях русского глагола, его спряжении и др., которые способны оказать существенную помощь студентам в эффективном изучении русских глаголов.

(C) Мохаммади Мохаммад Реза, Ахмади Мирейла, Бахарлу Хади, Галебанди Сейеде Сафура, 2020

\section{Список литературы}

1. Восканян Г.А. Русско-персидский словарь: ок. 3000 слов / Г. А. Восканян. М.: АСТ: Восток-Запад, 2008.

2. Девель Л.А. Двуязычная лексикография: алгоритм описания // Вестник СПбГУ: Сер. 9. Вып. 1. 2011. С. 84-90.

3. Кароматова З.Ф. Работа со словарем - эффективный способ изучения английского языка // Достижения науки и образования. Иваново: № 4. 2017. С. $81-82$.

4. Клевцова С.Д. Русско-персидский словарь / С. Д. Клевцова. Тегеран: Фаджре Ислам, 1995.

5. Методика преподавания русского языка как иностранного: учеб. пособие для вузов / А.Н. Щукин. М.: Высшая школа, 2003.

6. Овчинникова И.К. Русско-персидский словарь / И. К. Овчинникова. Мешхед: Джавдане Херад, 2005.

7. Прокудина О.А. Применение электронного двуязычного словаря при работе с текстами по специальности: теория и практика // Филологические науки. Вопросы теории и практики. o 7 (25). 2013, часть 1. 2013. С. $166-168$.

8. Ушаков Д.Н. Толковый словарь современного русского языка / Д.Н. Ушаков. М.: Аделант, 2013.

9. Частотный словарь русского языка / под ред. Л.Н. Засориной. М.: 1997.

\section{References}

1. Voskanian, G. A. Russko-persidskii slovar': ok. 3000 slov [Russian-Persian dictionary: about 3000 w.] / G. A. Voskanian; M., AST: Vostok-Zapad, 2008.

2. Devel', L. A. Dvuiazychnaia leksikografiia: algoritm opisaniia [Bilingual lexicography: description algorithm] // Vestnik SPbGU. Ser. 9. Vyp. 1. 2011. S. 84-90.

3. Karomatova, Z. F. Rabota so slovarem - jeffektivny sposob izucheniia angliskogo iazyka [Working with a dictionary -an effective way to learn English] // Dostizheniia nauki i obrazovaniia. Ivanovo: № 4. 2017. S. 81-82.

4. Klevtsova, S. D. Russko-persidskii slovar' [Russian-Persian dictionary] / S. D. Klevcova; Tegeran: Fadzhre Islam, 1995.

5. Metodika prepodavaniia russkogo iazyka kak inostrannogo: ucheb. posobie dlia vuzov [Methods of teaching Russian as a foreign language: Textbook. manual for universities] / A. N. Shhukin; M., Vysshaia shkola, 2003.

6. Ovchinnikova, I. K. Russko-persidskij slovar' [Russian-Persian dictionary] / I. K. Ovchinnikova; Meshhed, Dzhavdane Herad, 2005.

7. Prokudina, O. A. Primenenie elektronnogo dvuiazychnogo slovaria pri rabote s tekstami po special'nosti: teoriia i praktika [The use of electronic bilingual dictionary when working with texts in the specialty: theory and practice] // Filologicheskie nauki. Voprosi teorii I praktiki. № 7 (25). 2013. C. 166-168.

8. Ushakov, D.N. Tolkovy slovar' sovremennogo russkogo iazyka [Explanatory Dictionary of the Modern Russian Language] / D.N. Ushakov; M., Adelant, 2013.

9. Chastotny slovar' russkogo iazyka [Frequency dictionary of the Russian language] / pod red. L.N. Zasorinoi. M. 1997.

\section{Сведения об авторах:}

Мохаммади Мохаммад Реза - кандидат филологических наук, доцент кафедры русского языка государственного университета Тарбиат Модарес (Тегеран, Иран).

E-mail: mrmoham@modares.ac.ir 
Ахмади Мирейла - кандидат филологических наук, доцент кафедры русского языка государственного университета Тарбиат Модарес (Тегеран, Иран).

E-mail: mireyla@modares.ac.ir

Бахарлу Хади - кандидат филологических наук, старший преподаватель кафедры русского языка государственного университета Тарбиат Модарес (Тегеран, Иран).

E-mail: baharloo@modares.ac.ir

Галебанди Сейеде Сафура - аспирантка кафедры русского языка государственного университета Тарбиат Модарес (Тегеран, Иран).

Email: s.ghalebandi@modares.ac.ir

Конфликт интересов: Авторы заявляют об отсутствии конфликта интересов.

\section{About the authors:}

Mohammadi Mohammad Reza - Candidate of Philology, Russian language department, Associate Professor at Tarbiat Modares University.

E-mail:mrmoham@modares.ac.ir

Ahmadi Miryla - Candidate of Philology, Russian language department, Associate Professor at Tarbiat Modares University.

E-mail: mireyla@modares.ac.ir

Baharloo Hadi - Candidate of Philology, Russian language department, assistant professor at Tarbiat Modares University.

E-mail: baharloo@modares.ac.ir

Ghalebandi Seyedeh Safoora - a graduate student of the Russian language department at the Russian Language department at Tarbiat Modares University.

Email: s.ghalebandi@modares.ac.ir

Conflicts of interest: The authors declare absences of conflicts of interest. 